\title{
NATIONALISM IN CONTEMPORARY CHINESE ADVERTISING
}

Jing Wu

\section{Introduction}

This paper examines the nationalist elements in contemporary Chinese advertising and how advertising tries to connect particular economic interests with state-building agendas. Advertising as a business became irrelevant and stopped completely in China in late 1950's when the nationalization of all industries was finished and the institution of planned economy consolidated. It reoccurred in the late 70's and has enjoyed a considerable development ever since as the market mechanism was gradually reintroduced into China's economy as part of the vast reform effort ( $\mathrm{Xu} 3$ ). The process of economic reform, however, is fraught with contradictions. In theory, the state claims to stay loyal and committed to the socialist ideal of equality and justice, and continues to promulgate the collective-oriented social values that would underpin the legitimacy of socialism as a desirable state system for the nation. Yet the introduction of market economy as a means to enhance productivity has also brought in the logic of redistributing social wealth along the lines of capital and fostered values that undermine the hegemony of socialist ideology. The state is therefore engaged in the contradictory effort of articulating the two diverging tendencies into a productive dynamism. It sets up limits and regulations to redirect certain trajectories of the market, whose logic it helps to establish and legitimize. Advertising is an area where such efforts are registered.

As a means to connect production and consumption, advertising is an element through which distribution of social resources and reproduction of the economic system are actualized under market economy. At the same time, as a signifying activity, advertising also has ideological functions. Many have studied the role of advertising in constructing desirable subjects of consumption and reinforcing dominant social values in capitalist economies (Baker, 1968; Andren, 1978; Buzzi, 1968; Williams, 1993). In the endeavor to create a socialist market economy, the Chinese government intervenes into the market both institutionally 
and ideologically in order to affect certain channeling of social resources that the market logic would not encourage. In the realm of advertising, discourses of nationalism are sometimes mobilized to justify these interventions and restrictions on the market. Moreover, as an emotionally appealing ideology of collectivism, nationalism is incorporated into advertising messages to counterbalance the encouragement of individualism in creating desires for consumption and articulate individual interests with the socialist goal of collective betterment.

\section{Interventions in Advertising - Crisis Management of a Socialist Market Economy}

A defining element that makes China's market economy a "socialist" as opposed to a "capitalist" one is the predominance of socialized ownership of means of production. In China, the land, most heavy industries, communication, transportation and other "pillar" industries of the national economy are stateowned, many industries are collectively owned, ${ }^{1}$ and only a small percentage is private or foreign owned. Private and foreign owned industries and companies are subject to regulations and restrictions by the socialist state on the scope and nature of their conduct. They certainly enjoy less freedom in both business and political activities than private companies in capitalist countries.

Socialized ownership and market economy are not a smoothly cooperative couple. Because of their distinct priorities in conducting business, most business decisions are made as a compromise struggling to fulfill both ends or as a result of contest for dominance of one over another. The logic of market economy is to maximize profit for an individual company, whereas the purpose of socialized ownership is to care for the collective well being of an entire community. Since the ownership pattern is backed up by a complicated system of state apparatus, it assumes regulating power over the market economy. When the profit-seeking logic is in accordance with the interest of a larger collective, activities under the guidance of such logic are encouraged. When it contradicts with the goal of the latter, business activities are discouraged and restricted through legal and regulatory procedures. Taking the example of the business of advertising, Wang Jian in his dissertation draws our attention to a statement in $A$ Practical Handbook of Advertising in China, an official pamphlet to guide advertising activities - "one key characteristic of advertising is its relative strong ideological content." This shows that the state is aware of certain functions of advertising that contradict the stated goals of socialism. In the Advertising Law of PRC, it is also clearly stipulated that "advertising should be truthful, legal and in accordance with the demands of a socialist spiritual civilization" (Wang 170). Therefore, under a socialist market economy, enterprises seem to have more obligations to justify their business activities as socially beneficial. At the same time, they have relatively little lobbying and political power to ignore such obligations. Take another example from advertising, as Wang Jian describes how international ad agencies adapt the content of their commercials to abide by Chinese regulations:

In the face of the Advertising Law, the "supposedly unstoppable 
drumming bunny in the Duracell battery commercials came to a halt" in Beijing because the ads violated the no superlative and comparative advertising rule (Business Week, October 23, 1995, p.52). Neither was Budweiser's "King of Beers" claim acceptable (ibid.). An ad for Apple computer had to be revised because it involved implicit comparison with a competitor (interview with an ad executive in Beijing, May 1996)

(Wang 173).

However, this cannot be seen as a permanent condition, with the percentage of different ownership patterns in Chinese economy changing all the time, the confrontation between the two priorities does not always result in the victory of the socialized ownership.

Advertising, as the lubricant of market economy, is also part of the socialist market economy in China. To create consumer desire for certain products, Chinese advertising also needs to make use of socially available and largely appreciated values to enhance its credibility. In turn, the constant public positive communication of these values helps to reinforce their legitimacy and dominant position. To drive consumption as a desirable activity for the individual, Chinese advertising also incorporates values that can be found in capitalist countries, such as leisure, comfort, domesticity, and aspiration for social status, etc. However, what differentiates it from its capitalist counterpart is the availability of socially and collectively oriented concepts in strong competition with the former ones.

Nationalism is one of these concepts. The definition and rhetorical use of nationalism is subject to constraint of the dominant social system. Only when it is concretely articulated as the collective interest of the ruling classes during particular historical period can it be meaningfully connected to the promoted products in advertisements, which try to persuade the consumers that buying these products can help realize such an interest.

\section{A Concrete Understanding of Nationalism in Contemporary China}

The term nationalism has been mobilized in different times, different places and under different socio-cultural conditions to mean different and many times contradictory things, and to sustain different types of human practices. Though considered a different concept from "state," the word "nation" many times presumes or aspires to a "state" that materializes the "nation" in terms of geographical boundary and population composition (Anderson 7). Behind the rhetoric of nationalism, there are various intentions of practice - to mobilize support for a state-building effort, to drive out foreign invasions, to legitimize state policies, to consolidate and develop the present social system, or even to expand and conquer when the interest of a "nation" is constructed as lying in the suppression of others.

Besides the somewhat functional connection between nationalism and state agendas, "nation" and "state" have more substantial interconnections. The defining feature of a "nation" is usually a "common culture" rather than social institutions. However, culture as an established set of behavioral and life patterns 
formed through a process of collective negotiation is not created in a power-free environment. Among the many forces that constrain and direct cultural formation, social institutions under direct or indirect control by state apparatuses exert great power in shaping certain aspects of the culture of a community. With the passing of time, conspicuous power can be internalized as willing action of the majority of the community, with power losing the necessity of its physical existence. For instance, written Chinese was unified in Qin Dynasty after Qin conquered the other six kingdoms and formed a unified empire in $229 \mathrm{BC}$. The different written systems in the former six kingdoms were discarded by force. Contemporary written Chinese is developed from the unified system, the use of which is seldom "forced" but voluntary as people practice their own "culture." The shadow of state power is sometimes so distanced that its effect is conveniently taken as "culture" and the raw material to form the "nation," which is considered distinct from the state. In this sense, the "continuous nation," having its primordial traditions and evolving endlessly into the future, is nothing but myth. What we have today are different configurations of state inheriting "traditions" resulting from past power struggles and social transformations but painted as "eternal."

To separate "nation" from "state" not only obscures the influence of state power in forming the "nation" but also obscures the internal divisions and contradictions within the "nation." If the "state" can be seen as an apparatus of domination and control, the "nation" is oftentimes considered as "belonging" to all members of a community. Therefore, the interpellation of disadvantaged members of a society to participate willingly in the dominant social practices often takes the form of nationalism in order to disguise the internal fractures of the "state."

This is not to say that "nation" and "state" are entirely congruent entities. The degree of inter-penetrations between these two differs in different cases. Whether or not the national and state interests coincide depends on how the state is defined and how the state defines the nation. Nationalism, an ideology that links the state to the nation, only has social meaning when it is explained, articulated and activated under concrete social, historical and class conditions. There are no primordial and identifiable national interests and fates to be loved and defended permanently, only historically constrained interests of particular classes taking the rhetorical and institutional form of "the nation." Therefore, the interests of the "nation" is concretely articulated and practiced as the interests of the ruling coalition that holds the state power. Besides the similarities with other third world countries in nationalist discourse, such as economic development, sovereignty, and self-determination, contemporary Chinese nationalism is directly connected with particular state-building agendas inspired by socialist principles. The nation is defined as a socialist country based on the dictatorship of the working class and the coalition between workers and peasants. To love China is allegedly to love the country with such characteristics and to promote the national interests is to promote the interests of the workers and peasants who supposedly form the ruling block of the country. People are constantly reminded 
that the government is promoting these interests through state policies and propaganda of state policies. These interests are also concretely located and represented in the advertising rhetoric. Advertising, as both economic and cultural activity, is predominantly meaningful in the promotion of certain kinds of economic activities and the cultural affirmation of such activities in light of national interests.

\section{The Protection of National Industry Through Advertising}

Attracting foreign investment is considered an efficient way to develop the Chinese national economy. However, what comes together with foreign capital are not merely advanced technology and management, but also severe competitive pressure on the already vulnerable national industry. The danger of being devoured co-exists with the benefits of absorbing foreign capital under the free market condition of "survival of the fittest." In order to curb the excess of foreign competition in China, state regulations are established to protect the domestic industry through various forms of affirmative actions, such as limiting the range, type and authority of transnational corporations in China (Wang 112). In the realm of advertising, the rates for foreign or joint-venture ads are much higher than those for domestic products (Wang 117). Since most media institutions are still publicly owned and a complete market determination of advertising rates based on an "independent" rating system does not exist, Chinese media only play by the rules of the market when they are favorable to a higher agenda of boosting the national economy. Such protection is conducted not through direct exertion of state power in limiting the market of foreign companies nor through compulsory placement of domestic advertising in mass media, but through manipulating the advertising prices to create a favorable condition for domestic enterprises to promote their products, compensating their lack of experience on market research and capital to place large scale advertisements. In this way, the mechanism of the market economy is partially and conditionally utilized to serve a purpose that can hardly be achieved under the absolute domination of a "free" market.

The idea that national interests have priority over market principles is not only practiced in institutional arrangements of advertising but also further promoted in advertising messages. The slogan of a tape recorder commercial reads, "National products should have self-respect." This reminds people of the embarrassing condition of China's electronic industry facing foreign, especially Japanese competition. Decades of planned economy had placed emphasis on the heavy industry, making little preparation for the national light industry to face a rival with capital, technology and experience. By including itself as a member of "national products" and by claiming self-respect on behalf of all of them, the commercial connects the fate of one product with that of an entire industry. Since industrial success is considered, among nation states, a major index of national achievement and an important basis of national strength, the interest of the tape recorder manufacturer is ultimately connected with the interests of the "nation." To claim "self-respect" is a gesture on the side of the industry to promise 
devotion to the cause of national development. The message implicitly encourages the audience to do their part in contributing to this cause, i.e. buying more domestic made products, including the tape recorder. One key premise of the availability of this type of advertising is the existence of a social value that economic activities, even activities of consumption, have significance and effects on a cause larger than individual satisfaction. By mobilizing it to promote a product, such commercials reconfirm and reproduce such a social value.

The slogan of a liquor commercial reads, "Carry on the spirit of the Long March and rejuvenate the national industry." The reference to the Long March of the Red Army is not arbitrary. It presumes some background knowledge by the audience. The place where the liquor is produced - Zunyi - is also the place where a historically important conference of the Chinese Communist Party was held in 1935. In that conference, Mao Zedong's strategies were supported by the majority of the Red Army officers and those who dogmatically followed Soviet instructions were removed from leadership positions (Uhalley 49). After the conference, Mao and his colleagues led the devastated Red Army through the famous Long March, an important step toward the ultimate victory of the socialist revolution in 1949. The Zunyi conference is thus considered the turning point in the history of the Chinese Communist Party and is well known because of its frequent mention in mass media and textbooks.

In this commercial, the interest of the "state" and the interest of the "nation" are one and the same. A significant conference that changes the fate of a party seeking state power is also considered a landmark instance that transforms the future of the "nation." "The spirit of the Long March" leads to the victory of the socialist state system in China and it needs to be carried on in order to "rejuvenate the national industry." The "nation" here is concretely defined during a particular historical period and under a particular social system. The mass circulated slogan - only socialism (form of state) can save China (the nation) - is skillfully and unconsciously transformed into a commercial message, in which the socialist ideology is no longer conspicuously called out and asserted, but serves as a taken-for-granted background. This might represent a stage when certain hegemony has been formed and social consensus to some degree has been achieved. The unproblematic mobilization in commercial messages of the value that associates socialism closely with China's national interests serves in turn to consolidate the social consensus over such a value.

\section{The Use of Advertising to Approach the Socialist Goal of Collective Better- ment}

In his “Advertising: the Magic System," Raymond Williams concludes that "the conflict between capitalism and socialism is now commonly seen in terms of a competition in productive efficiency, and we need not doubt that much of our future history, on a world scale, will be determined by the results of this competition" (Williams 423). This understanding is also embraced by the Chinese Communist Party in the reform era starting from the late 70 's. It is commonly agreed that the advantages of socialism over capitalism have to be practically 
demonstrated rather than merely theoretically asserted (Uhalley 212). The claim that in socialist countries the working people own the means of production needs to be translated into actual personal profits gained from such ownership. Under contemporary global conditions, the competition between socialism and capitalism oftentimes takes the form of competition between nations that adopt different social systems, despite the ultimate socialist orientation toward internationalism. This state of things is already envisioned by Marx when he claims that "in form, the struggle of the proletariat with the bourgeoisie is at first a national struggle and the proletariat of each country must, of course, first of all settle matters with its own bourgeoisie" (Marx 482). It seems now that the process of "national struggles and development" persists for a much longer period of time than anticipated by many socialist theories and movements. Under the condition of severe competition among social systems to win the support of the "nation," the pragmatic approach of the Chinese Communist Party is that the primary task of the state today is to find whatever ways available to realize the socialist promise of a collective betterment of the people's actual living standards. Only then can socialism really legitimize itself as the best choice of the "nation" and pose as a strong competitor to be accepted by other "nations" in the world.

One of the ways to quicken economic development is to conditionally adopt certain forms of economic activity existing in capitalist countries, such as regulating production, circulation and exchange through market principles. However, one persistent result of market competition is the gradual polarization of wealth distribution, which inherently contradicts the socialist commitment to the collective betterment of life. The negative effect of market economy has already begun to be felt in the deepening economic gap between coastal areas and the inland of China. Investments tend to concentrate in places that have favorable natural environment and better industrial infrastructure to facilitate economic activities. Agricultural areas in central China are largely ignored by investors while they are in great need of financial and technical input to modernize traditional agricultural production.

The systematic victimization of particular sections of the population is considered detrimental to the national interest, in light of the socialist conceptualization of the "nation." Therefore, the state efforts step in to mitigate imbalances and inequalities caused by pure market forces. Among those efforts is CCTV's ${ }^{2}$ special program - TV Commercials for Poverty Release. The set of messages are shown in regular commercial slots at different times of the day, ${ }^{3}$ headed with a short introduction by a voice over,

In order to carry out the Party's policy to support agriculture, CCTV is now showing Poverty Release commercials. Please pay attention to the information and if interested, contact relevant parties.

Though they are called poverty release commercials by CCTV, the content is entirely different from what people usually consider charity commercials, in which audiences are appealed to donate money or things for the poor. Each commercial in the group briefly introduces a particular type of agricultural product, which is the specialty of a poor area in the country, and provides 
telephone numbers for people who are interested in finding a market for these products. These commercials play the role of information providers to introduce products that are potentially useful and profitable but are neglected because of lack of efficient communication. Unlike charities that only aim to ease the immediate sufferings of the poor, the purpose of these poverty release commercials is to eradicate the cause of poverty by helping to establish stable relationships between agricultural products of the poor areas and the markets outside. By moving into the market circulation, traditional agriculture will be able to accumulate capital on a much larger scale and launch onto the route of sustainable development based not on the mercy of heaven but the forces of the market.

These commercials possess the common characteristic of advertising, which is to promote particular products and help realize their value through exchange. At the same time however, they are not merely commercials but practices of specific kinds of state interventions. The production and placement of these commercials are not pure business activities but social responsibilities carried out by a publicly owned television station. Since these commercials are aimed at poverty release, it is obvious that the communities whose products are promoted do not have the ability to finance these commercials at usual market prices and CCTV carries them free of charge (Fan 15). By highlighting the special position of these commercials in contrast to others in the brief introduction, the messages transcend the limited purpose of advocating a single product and serving the interest of an individual owner. They place these preferred economic activities as integral parts in the larger picture of nation building. This is further manifested in the particular ways of visual and verbal mobilizations in the content of these commercials.

When introducing products, all of the commercials present them as belonging to people of particular places, rather than companies, factories, or any other types of economic entities. The telephone numbers left for interested audience to contact belong to the People's Government of Daming County, Office for Kiwi Production, or the County Laboratory for Developing Chinese Medicine, etc. All these foreground the essentially different economic basis these commercials reproduce from that of a capitalist society - socialized ownership. Based on the pre-condition of public ownership, it is implied in those messages that profits gained through the exchanges promoted by the commercials will also benefit the community as a whole. This is easily translatable to notions of "nation" and "national interest," for the socialist "nation" is concretely defined as a "nation" where the majority of the population owns the basic means of production collectively. In light of this assumption, CCTV claims in these commercials that the policy to support agriculture in underdeveloped areas is "beneficial to both the country and the people."

In invoking the concept of "nation," this set of commercials portrays ideologically defined images of the "national subjects" as the embodiment of the "nation." The central players shown in the pictures while the sound track is introducing a particular agricultural product are producers rather than consumers of the product. They are the people who smile into the camera holding the fruit of 
their own labor, who are busy working in the field, or who are dancing in festivals celebrating the harvest. This poses a sharp contrast to most commercials in which the consumer, rather than producer, is centrally associated with the product. To use Marx's notion of alienation, advertising in a predominantly capitalist environment reproduces symbolically the institutional separation of the laborer and the laboring process from the product. Products in these advertisements "belong" to the consumer. They are celebrated for their ability to "enhance" the consumer's social status as an individual and their connections with the laborer are obscured. The symbolic erasure of the laborer reflects and reproduces the social segregation of the worker and the consumer in the sense that oftentimes those who produce are not those who consume. However, in the set of CCTV commercials under study, the producers are owners of their products and the primary function of these products is to enhance the happiness of their creators. The messages appeal to the audience to contribute to the realization of such happiness by establishing business relationships that will also serve their own interests. The pictures imply that the harmonization of the producer and the consumer into the same body is only possible under the condition of socialized ownership.

The contrast, developed by Schudson, between socialist realism in state propaganda and capitalist realism in advertising can be used here to make sense of the social significance of centering the producers rather than consumers in these commercials. In socialist propaganda, according to Schudson, the people are represented as happy workers of the state. By portraying this way of life as productive and desirable, the propaganda encourages the people to follow the idealized pattern of conduct. In capitalist advertising, a similar mechanism is also at work, but in different forms. Advertisements in capitalist societies associate the "good life" not with state building but with the consumption of commodities, and thus they ask the audience to live the life of consumers (Schudson 218). Here, realism is not a form that portrays reality but one that dictates what reality should be. In presenting the laborers as the "national subjects" that have control over the production, distribution and consumption of their products collectively, the CCTV commercials idealize a particular way of life and inspire the people to act in ways that can actualize such a way of life. In this sense, socialist realism can also work in advertising, a form of communication that Schudson associates exclusively with capitalism. By reproducing the ideal concept of reality, these commercials encourage practices that orient toward its actualization in real life.

\section{Conclusion}

This paper has examined how nationalism is concretely defined and used in the present Chinese economic system. The socialist market economy has two opposing tendencies, each vying to dominate the other. On the one hand, the mechanisms of competition introduced by market economy inject energy into an economy that was inflicted by inefficiency, bureaucracy and thus poverty. It helps to re-envision socialism as a social system seeking equality based on abundance rather than scarcity. On the other hand, however, the same mechanisms of 
competition, left alone to work on their own, will inevitably jeopardize the ideal of equality as the defining feature of socialism. Efforts are made to strengthen the first tendency and control the excess of the second one. Using advertising to mobilize concrete nationalist emotions and create aspirations to a collective way of life is one of those efforts.

This paper only focuses on the institutional and textual intentions of specific advertising activities and the social conditions of possibility for such activities to exist and prosper. There is no guarantee that these intentions of reconciling the present contradiction can always be realized in every particular case, nor does it mean that the power relationship between two sides of the contradiction will not change over time. As part of the effort to get into the World Trade Organization, China has promised to eliminate all domestic laws and regulations that are in conflict with international trade establishment. It remains to be seen how China is able to maintain a socialist identity by integrating itself into the capitalist global market. It could be a future research topic to trace the changes in the value systems mobilized by commercials, which give insight into the transformed social conditions and the state of contradiction under which commercials are produced.

\section{Works Cited}

Anderson, Benedict. Imagined Communities: Reflections on the Origin and Spread of Nationalism ( $2^{\text {nd }}$ ed.). London: Verso, 1991.

Baker, Samm Sinclair. The Permissible Lie. New York: World Publishing Company, 1968.

Andren, G., Ericsson, L.O., Ohlsson, R. \& Tannsjo, T. Rhetoric and Ideology in Advertising: A Content Analytical Study of American Advertising. Stockholm: AB Grafiska Gruppen, 1978.

Buzzi, Giancarlo. Advertising: Its Cultural and Political Effects (trans. By B. DavidGarmize). Minneapolis: University of Minnesota Press, 1968.

Fan, Lubin. "Advertising 1997" in China Advertising (Zhong Guo Guang Gao). 1998:3.12-15.

Marx, Karl. "The Grundrisse." The Marx-Engels Reader (2 ${ }^{\text {nd }}$ edition). Ed. Robert C.Tucker. New York: W.W. Norton \&Company, Inc., 1978. 221-293.

---. "Manifesto of the Communist Party." The Marx-Engels Reader (2 ${ }^{\text {nd }}$ edition). Ed. Robert C. Tucker. New York: W.W. Norton \& Company, Inc., 1978. 469-500.

Schudson, Michael. Advertising, the Uneasy Persuasion: Its Dubious Impact on American Society. New York: Basic Books, 1984.

Uhalley, Stephen. A History of the Chinese Communist Party. California: Hoover Institution Press, 1988.

Wang, Jian. Becoming Global, Becoming Local: The Multinational Advertising Industry in China. Doctorate Thesis. Graduate College of University of Iowa, 1997.

Williams, Raymond. "Advertising: the Magic System." The Cultural Studies 
Reader. Ed. Simon During. London and New York: Routledge, 1993. $410-423$.

Xu, Baiyi. Marketing to China: One Billion New Customers. Lincolnwood: NTC Business Books, 1991.

\begin{abstract}
Notes
${ }^{1}$ State-ownership means all citizens in the country theoretically have an equal share in the property of a business entity. Collective-ownership means the property is equally owned by those who work in the institution.

${ }^{2}$ CCTV represents China Central Television, the only national TV network in China besides cable.

${ }^{3}$ I saw these commercials in three different slots at different times. One was after a variety show to celebrate the Moon Festival, one before a children's program and one before a TV drama about student life in a military medical school.
\end{abstract}

